\title{
Viral vectors for cystic fibrosis gene therapy: What does the future hold?
}

This article was published in the following Dove Press journal:

Virus Adaptation and Treatment

14 December 2010

Number of times this article has been viewed

\author{
Uta Griesenbach' \\ Makoto Inoue ${ }^{2}$ \\ Mamoru Hasegawa ${ }^{2}$ \\ Eric WFW Alton' \\ 'Department of Gene Therapy, \\ Imperial College London, UK; \\ The UK Cystic Fibrosis Gene Therapy \\ Consortium; 'DNAVEC Corporation, \\ Tsukuba, Japan
}

\begin{abstract}
Gene transfer to the airway epithelium has been more difficult than originally anticipated, largely because of significant extra- and intracellular barriers in the lung. In general, viral vectors are more adapted to overcoming these barriers than nonviral gene transfer agents and are, therefore, more efficient in transferring genes into recipient cells. Viral vectors derived from adenovirus, adeno-associated virus, and Sendai virus, which all have a natural tropism for the airway epithelium, have been evaluated for cystic fibrosis (CF) gene therapy. Although these vectors transduce airway epithelial cells efficiently, gene expression is transient and repeated administration is inefficient. They are, therefore, unlikely to be suitable for CF gene therapy. More recently, lentiviruses (LV) have been assessed for lung gene transfer. In contrast to retroviruses, they transduce nondividing cells and randomly integrate into the genome. However, LVs do not have a natural tropism for the lung, and a significant amount of effort has been put into pseudotyping these vectors with proteins suitable for airway gene transfer. Several studies have shown that LV-mediated transduction leads to persistent gene expression (for the lifetime of the animal) in the airways and, importantly, repeated administration is feasible. Thus, appropriately pseudotyped LV vectors are promising candidates for $\mathrm{CF}$ gene therapy. Here, we will review preclinical and clinical research related to viral $\mathrm{CF}$ gene therapy.
\end{abstract}

Keywords: cystic fibrosis, gene therapy, adenovirus, AAV, lentivirus, Sendai virus

\section{Introduction}

$\mathrm{CF}$ is the most common lethal autosomal recessive disease in the Caucasian population and affects $\sim 70,000$ individuals worldwide. Although several organs are affected, severe lung disease is the cause of most of the morbidity and mortality in CF individuals. ${ }^{1}$ The CF gene, the cystic fibrosis transmembrane conductance regulator (CFTR) was cloned in $1989^{2}$ and is a chloride channel located in the apical membrane of epithelial cells. Mutations in the CFTR gene lead to imbalanced ion and water movement across the airway epithelium, resulting in accumulation of sticky mucus, chronic bacterial infection, and inflammation. CF is a single-gene disorder with insufficient treatment options and comparatively easy access to the target organ, the lung, and was, therefore, one of the first diseases to be considered for gene therapy. Following cloning of the gene, proof-of-principle for CFTR gene transfer was quickly established in vitro and in animal models., ${ }^{3,4}$

Various viral and nonviral gene transfer agents (GTAs) have been assessed, and since cloning of the CF gene in 1989, 25 phase I/II clinical trials, involving $\sim 420 \mathrm{CF}$ patients, have been carried out using a variety of viral and nonviral GTAs. However,
Correspondence: Uta Griesenbach Department of Gene Therapy, Faculty of Medicine at the National Heart and Lung Institute, Imperial College London, Manresa Road, London SW3 6LR, UK Tel +44 207 35I 8339

Fax +44 2073518340

Email u.griesenbach@imperial.ac.uk 
the question whether CFTR gene transfer can ameliorate $\mathrm{CF}$ lung disease has not been conclusively addressed till date. This review will focus on reviewing literature related to viral vectors for $\mathrm{CF}$ (Table 1); the status of nonviral $\mathrm{CF}$ gene therapy has been recently reviewed. ${ }^{5}$

\section{Barriers to airway gene transfer}

The lung is a complex organ and can be roughly divided into two main regions: the airways, consisting of trachea, bronchi, and bronchioles which transport air to the peripheral lung; and the alveoli where gas exchange takes place. The lung has evolved to fight invasion of foreign particles, and GTAs have to overcome a number of extra- and intracellular barriers to achieve their objective. ${ }^{6}$ The relative strengths and weaknesses of viral and nonviral GTAs in overcoming these barriers will be briefly discussed below.

The most significant extracellular barriers are arguably respiratory secretions. Mucins secreted by goblet cells and submucosal glands play an important role in host defense because they trap inhaled particles, including GTAs, which are subsequently cleared through cough and mucociliary clearance mechanisms. Importantly, lung infection and inflammation which is a characteristic hallmark of CF lung disease further enhances this barrier. Inflammatory cells and bacteria release actin and genomic DNA which contributes to accumulation of viscous sputum in the CF lung. CF sputum has been shown to be a significant barrier to nonviral gene transfer, ${ }^{7,8}$ but importantly does not appear to affect viral vectors, such as Sendai virus ( $\mathrm{SeV}$ ) and adenovirus (Ad), to the same degree. ${ }^{7,8}$ The airways down to the level of the primary bronchioles are lined by ciliated airway epithelial cells (AEC). Cilia present a significant barrier for nonviral and viral GTAs, and cilia-static agents such as methylcellulose and carboxymethyl cellulose have been shown to significantly increase viral and nonviral pulmonary gene transfer, respectively, in mice. ${ }^{9,10}$
In addition to the physical barriers listed above, the immune surveillance in the lung is a major barrier and is more likely to affect viral than nonviral gene transfer. The presence of antibodies due to prior infection with wild-type viruses is a particular problem for Ad and adeno-associated viruses (AAV) because almost all people have antibodies against Ad5 and AAV2, two of the most commonly used viral vectors, although the antibodies do not always neutralize virus infectivity. ${ }^{11}$ In addition to preexisting antibodies, cellular and humoral immune responses can develop after administration of the viral vector, which may render subsequent virus administration ineffective. The capacity to induce immune responses and allow repeat administration is vector-dependent and will be discussed in the relevant sections below. Importantly, nonviral vectors are less likely to induce immune responses, and consistent efficacy after repeat administration has been demonstrated in preclinical $^{12}$ and clinical studies. ${ }^{13}$

Although various pulmonary cells express CFTR (albeit at low levels), the ciliated AECs are, in our view, currently the most relevant targets for CF gene therapy. However, these cells have comparatively low endocytosis rates at the apical membrane, which significantly affects nonviral GTAs as these are predominantly internalized via endocytosis. In general, viral vectors require specific cellular receptors for cell entry by either endocytosis or membrane fusion and these receptors may not be expressed at the apical membrane of ciliated AEC. The coxsackie-adenovirus receptor, for example, is only expressed at the basolateral membrane of AEC, ${ }^{14}$ and efficient Ad-mediated gene transfer can only be achieved if the virus is coadministered with agents that open tight junctions (see below). In contrast, cholesterol and sialic acid residues, which are required for $\mathrm{SeV}$ to enter cells, are present at the apical membrane. This, in part explains the high transduction efficiency of this virus. ${ }^{8,15}$ More details

Table I Viral vectors used in CF gene therapy

\begin{tabular}{|c|c|c|c|c|}
\hline & Name & Genome & Cell localization & Host genome integration \\
\hline \multirow[t]{3}{*}{ DNA viruses } & Adenovirus & $\begin{array}{l}\text { Linear, double- } \\
\text { stranded DNA }\end{array}$ & Nuclear & No \\
\hline & $\begin{array}{l}\text { Adeno-associated } \\
\text { virus (AAV) }\end{array}$ & $\begin{array}{l}\text { Linear, single- } \\
\text { stranded DNA }\end{array}$ & Nuclear & Very little \\
\hline & $\begin{array}{l}\text { Simian vacuolating } \\
\text { virus (SV40) }\end{array}$ & $\begin{array}{l}\text { Circular double- } \\
\text { stranded DNA }\end{array}$ & Nuclear & Yes \\
\hline \multirow[t]{3}{*}{ RNA viruses } & $\left.\begin{array}{l}\text { Negative-strand } \\
\text { cytoplasmic virus }\end{array}\right\} \mathrm{SeV}, \mathrm{RSV}$ PIV & Linear nonsegmented RNA & Cytoplasmic & No \\
\hline & Retrovirus & Linear RNA & Nuclear & Yes \\
\hline & Lentivirus & Linear RNA & Nuclear & Yes \\
\hline
\end{tabular}

Abbreviations: SeV, sendai virus; RSV, respiratory syncytial virus; PIV, human parainfluenza virus. 
and other specific examples will be provided in the relevant sections below.

As mentioned above, nonviral vectors are generally internalized via endocytosis and efficient escape from endosomes is a significant bottleneck for these vectors, with a large proportion of nonviral vectors entering the lysosomal degradation pathway. Uptake of viral vectors is either by membrane fusion (for example, $\mathrm{SeV}$ and lentivirus (LV)) thereby avoiding the endosomal compartment or by endocytosis (for example, Ad and AAV). However, during evolution, viruses have developed efficient strategies to escape the endosome either through membrane fusion (for examples, influenza virus utilizes the surface protein hemagglutinin) or by endosome lysis or pore formation (for example, the penton base of $\mathrm{Ad}$ is involved in membrane disruption). ${ }^{16}$

The next step for most GTAs, with the exception of cytoplasmic expression vectors such as $\mathrm{SeV}$, is migration through the cytoplasm and nuclear entry. The nuclear membrane is a significant barrier for nonviral GTAs, and various strategies are being assessed to overcome this barrier including the addition of nuclear localization signals and incorporation of transcription factor binding sites into the plasmid backbone. ${ }^{17}$ In contrast, viral vectors have evolved appropriate strategies to enter the nucleus efficiently. After escape from endosomes Ad, for example, travels along microtubules to the nucleus. In close proximity to the nuclear pore complexes, the $\mathrm{Ad}$ genome is released from the capsid with the help of cellular proteins and the DNA enters the nucleus. ${ }^{16}$ In contrast to Ad, the AAV genome appears to be uncoded from the capsid after nuclear entry, although only a small proportion of virus particles actually enters the nucleus. ${ }^{18} \mathrm{LVs}$ enter the cells through cell fusion which releases the preintegration genome and associated viral protein into the cytoplasm where they interact with the cellular nuclear transport machinery and gain efficient entry via the nuclear pore complex in nondividing cells. ${ }^{19}$

With the exception of overcoming preexisting immune surveillance and inducing cellular and humoral responses after administration, viral vectors are more efficient in overcoming extra- and intracellular barriers than nonviral vectors generally leading to higher gene transfer efficiency in difficult-to-transfect tissues such as the airway epithelium. It is, therefore, not surprising that viral vectors have been extensively studied in the context of CF gene therapy. The current preclinical and clinical experience of viral vectors in the context of $\mathrm{CF}$ will be discussed below, describing the viruses in the order they were first studied.

\section{DNA viruses}

\section{Adenoviral vectors}

Adenoviruses are nonenveloped, nonsegmented, linear double-stranded DNA viruses which have a natural tropism for lung and respiratory infection and can cause the common cold, pneumonia, and bronchitis. Numerous serotypes have been identified, but most gene transfer vectors are based on type 5 , which causes mild respiratory infection in man. First-generation adenoviral vectors have a deletion of the E1 region, which encodes proteins required for replication, thereby rendering virus replication defective. Latergeneration viruses have more complex genome deletions culminating in the generation of 'gutless' viruses which are completely devoid of viral genome (see below). ${ }^{20}$ Adenoviral vectors do not integrate into the host genome, but remain episomal.

Due to a natural tropism for the target organ, adenoviral vectors were an obvious first choice for CF gene therapy and the first ever CF gene therapy trial was carried out with an adenoviral vector just a couple of years after cloning the CFTR gene in 1989. Zabner et al administered Ad-CFTR to the nasal epithelium of three CF patients. ${ }^{21}$ The nasal epithelium was initially chosen as a target organ, because the cell composition is similar to the lower airways and efficacy endpoints were easier to assess. In addition, administration to nasal epithelium was considered to be a safer option for early proof-of-principle studies than direct administration to the lung, although later studies demonstrated that the unique environment of the inflamed and infected CF lung constitutes an environment that cannot be easily recapitulated in noses of CF subjects or lungs of healthy volunteers. Due to the low number of subjects treated by Zabner et al $(n=3)$, conclusions about efficacy were difficult to draw, but the study opened the door for the additional nine adenovirus CF gene therapy trials that were carried in nose and lungs of CF patients between 1993 and 2001.5 Taken together, these trials showed that i) low-level gene transfer can be achieved in some subjects based on detection of vectorspecific CFTR mRNA and protein, ii) partial correction of the CF-specific ion transport defect, specifically the chloride transport, can be achieved in nasal epithelium of some patients, iii) adenovirus administration can cause side effects (lung inflammation), but this effect is dosedependent, iv) efficacy in general was lower than originally predicted by the preclinical models, v) administration of adenoviral vectors-induced humoral and cellular immune responses, which vi) importantly affect efficacy after readministration of the virus. 
In parallel to the clinical adenovirus studies described above, a large body of preclinical work has been conducted in an attempt to overcome the shortcomings of the vector for $\mathrm{CF}$ gene therapy. i) Access to the coxsackie-adenovirus receptor on the basolateral membrane of epithelial cells was gained through opening of the tight junctions with a variety of pharmacological agents including sodium caprate, ${ }^{22}$ perfluorochemical, ${ }^{23}$ and more recently lysophosphatidylcholine ${ }^{24}$ all leading to increased adenovirus-mediated gene transfer in the lungs of animal models. However, a controversial issue is whether such tight-junction openers can be used clinically, given the heavy bacterial colonization present in the CF lung and the attendant risk of systemic invasion. ii) Attempts have also been made to overcome the potent induction of cellular and humoral immune responses to the virus, which is currently the major bottleneck. Strategies such as administration of immunosuppressants and corticosteroids, ${ }^{25}$ and treatments aimed at transiently blocking $\mathrm{CD}^{+}{ }^{+} \mathrm{T}$ cells ${ }^{26}$ have been evaluated. However, the success of these strategies has been limited. In general, repeated administration was possible twice, but ultimately leads to reduced and finally absent transgene expression. The only exception so far is a report by Kolb et al, who demonstrated that administration of the steroid budesonide enabled adenovirus to be readministered at least five times without loss of transfection efficiency, ${ }^{27}$ but to the best of our knowledge, these findings have not been reproduced in other studies. iii) A better understanding of adenovirus biology led to the development of helper-dependent ('gutted') adenoviral vectors, which are depleted of all viral genes and, therefore, promised to be less immunostimulatory and may have improved safety profiles compared to first- and second-generation viruses, which have only a subset of viral genes deleted. Importantly, helper-dependent adenoviruses fulfilled some of these expectations and when administered, in combination with tight-junction openers, showed high-level and longer lasting gene expression compared to previous generations of the virus. In addition, inflammatory responses after virus administration were reduced. ${ }^{28}$ However, problems related to readministration of the virus persist ${ }^{28}$ and will need to be resolved too before adenoviral vectors can make a comeback in the field of CF gene therapy.

Despite the limitations for human use, adenoviral vectors have proven useful for preclinical proof-of-principle studies. Two studies have shown that adenovirus-mediated CFTR expression (or the consequent virus-induced inflammatory responses) may, to a degree, protect $\mathrm{CF}$ mice from the effects of bacteria-induced lung inflammation. ${ }^{29,30}$ Two studies disproved the suggestion that transient adenovirus-mediated
CFTR expression in utero prolonged survival of CF knockout mice, ${ }^{31-33}$ thereby, contributing to the debate about the role of CFTR during in utero development. However, CF knockout pigs have severe gastrointestinal pathology at birth, and the role of CFTR during in utero development requires further investigation. ${ }^{34}$

\section{Adeno-associated virus}

AAVs are single-stranded linear DNA viruses with a comparatively wide tissue tropism. Importantly, they are not associated with any known human pathology and appear to induce mild immune responses leading to a good safety profile, broad tissue tropism, and comparatively long (months) duration of expression, which explains their popularity for gene therapy-based applications. Although the wild-type virus integrates into a specific position on human chromosome 19 , it is generally believed that modified recombinant AAV gene transfer vectors do not integrate at high frequency, but rather remain as episomal constructs in the nucleus. ${ }^{35-37}$

AAV2 was the first and is currently the most extensively studied serotype. In the field of CF gene therapy AAV2based vectors quickly superseded Ad vectors in early 2000, and between 1999 and 2007six clinical studies were carried out mainly led by Targeted Genetics Corporation in which the vector was administered to the nose, sinuses, and lungs of CF patients. ${ }^{38}$ Initial single-dose phase I trials demonstrated that virus administration to the $\mathrm{CF}$ airways was safe, but provided little opportunity to assess efficiency of vector-specific CFTR expression. Subsequently, a phase-II trial further assessing the safety and efficacy of repeated administration (three doses, 1 month apart) of AAV2-CFTR was carried out. ${ }^{38}$ Viral shedding and increases in AAVneutralizing antibodies were noted, but virus administration remained safe. A significant reduction in sputum interleukin 8 (a proinflammatory cytokine) and a small improvement in lung function $\left(\mathrm{FEV}_{1}\right)$ were seen after the first, but not second or third administrations. On the basis of these studies, Targeted Genetics Corporation initiated a large repeatadministration study (100 subjects), sufficiently powered to detect significant changes in lung function. Although the vector was well tolerated, the study did not meet its primary efficacy end point of statistically significant improvement in lung function ${ }^{39}$ and the CF program at Targeted Genetics was discontinued in 2005. There may be several reasons for these disappointing results: i) AAV2 is too inefficient in transducing AECs via the apical membrane, ii) the long terminal repeat (LTR) promoter, which was used to drive 
expression of the $4.7 \mathrm{~kb} C F T R$ cDNA due to the limited packaging capacity (about $5 \mathrm{~kb}$ ) of the virus, is too weak, and/or (iii) repeat administration of AAV2 to the lung is not possible due to the development of an antiviral immune response. Research aimed at addressing and improving these potential limitations of AAV has been actively pursued (see below).

In addition to AAV2, a large number of alternative AAV serotypes have been identified in recent years, ${ }^{40}$ and capsids from serotypes $1,5,6,8$, and 9 appear to be more efficient in transducing AECs than AAV2. ${ }^{41}$

The atomic structure of AAV2 has also been identified, which may enable rational engineering of vector capsids for specific cell targeting. ${ }^{42,43}$ Shi et al have identified specific regions within the capsid protein that can tolerate the insertion of small exogenous peptides and have made an attempt at incorporating integrin-targeting peptides into this region. More recently, White et al have employed a similar strategy and incorporated various peptide ligands into the G-H loop of the capsid protein. One of the constructs successfully transduced polarized epithelial cells. ${ }^{44}$

Molecular evolution studies based on DNA shuffling and related recombination techniques are currently being utilized to generate new AAV vectors. ${ }^{45}$ Excoffon et al identified a recombinant $\mathrm{AAV}$ virus that transduced organotypic human lung cultures 100-fold better than parental strains, although the performance of this novel virus in human lung remains to be established. ${ }^{46}$ Along similar lines, Li et al have generated a chimeric AAV capsid-containing components of AAV1, 6, and 9 capsids $^{47}$ and shown that the chimera transduced differentiated AECs more efficiently than the parental strains. Interestingly, transduction of CF airway epithelium ex vivo achieved partial $(\sim 25 \%)$ correction of the chloride transport defect. Although a variety of novel AAV vectors have been generated through the various approaches described above, assessment of efficiency in the various models may not predict performance in man. Thus, Liu et al have reported that the airway tropism and, therefore, transduction efficiency for AAV serotypes is species-specific, ${ }^{48}$ which leads to yet unresolved questions about appropriate model systems for selection of the most efficient AAV serotype for the human lung and indicates that only clinical trials reliably and conclusively assess efficacy of different vectors in human lung.

In addition to alterations to the AAV itself, pharmacological interventions may also improve AAV transfection. Proteasome inhibitors, for example, have been shown to increase AAV2 and AAV2/5 transfection in vitro and in vivo ${ }^{49-51}$ probably via increasing their chances of transit to the nucleus.

Strategies to overcome the AAV packaging problem, thereby allowing incorporation of stronger promoters in addition to the large CFTR gene, have been developed, including approaches based on trans-splicing ${ }^{52}$ and homologous recombination. ${ }^{53}$ The basic principle of these techniques is to split the therapeutic cDNA and required promoter elements, and package them into two viruses, which when transfecting the same cell may recombine and generate a full-length therapeutic gene. One would speculate that both of these strategies would lead to reduced transfection efficiency, when compared with administration of one intact virus to the lung. However, surprisingly, Halbert et al have demonstrated that AAV2/6 (ITR from AAV2 and capsid from AAV6) recombination-dependent vectors transduced lung cells in mice almost as efficiently as intact vector, with $10 \%$ of AECs being positive. ${ }^{53}$ In addition, Song et al have shown that full-length CFTR mRNA, protein and chloride channel function can be generated in a CF airway epithelial cell line. ${ }^{54}$ However, the suitability for these approaches in the human lung remains to be established.

Shortening the CFTR cDNA is an alternative approach that has been developed to overcome the AAV packaging problems. For example, Ostedgaard et al have shown that a CFTR cDNA in which a portion of the R-domain has been deleted leads to partial correction of chloride transport in vitro $^{55}$ and Fischer et al established proof-of-principle that AAV2/5 carrying a truncated CFTR cDNA leads to vector-specific mRNA and protein expression in nonhuman primates. ${ }^{56}$ More recently, Mueller et al have shown that AAV-mediated expression of a truncated CFTR gene leads to partial correction of the allergic bronchopulmonary aspergillosis which can be associated with CF lung disease in a murine model. ${ }^{57}$ Although truncated CFTR protein appears to retain some of the known protein functions, there is currently no guarantee that all functions of this complex protein are retained if the coding sequence is partially deleted. Interestingly, Allocca et al have recently demonstrated that the packaging capacity may well be serotype-specific. ${ }^{58}$ The authors showed that in contrast to other serotypes, AAV2/5 was able to incorporate up to $8.9 \mathrm{~kb}$ of DNA and may, therefore, more easily harbor the $4.7 \mathrm{~kb} C F T R$ cDNA plus suitable regulatory elements. In addition to modifications in vector serotype and the cDNA, Halbert et al have shown that selection of the promoter/enhancer elements is important for transduction efficiency. In the context of AAV2/5, the CAG hybrid promoter consisting of a CMV enhancer, a beta-actin 
promoter and splice donor, and a beta-globin splice acceptor was most effective and led to $>90 \%$ transduction efficiency in mouse airways. ${ }^{59}$

It has been postulated that AAV may not infect antigenpresenting dendritic cells and thereby, avoid activation of the host immune system. However, the feasibility of repeated AAV administration is still unresolved. Results have varied greatly and may depend on the host, delivery route, and AAV serotype tested. ${ }^{60-62}$ Although the unsuccessful AAV2 repeat-administration trial (see above) may argue for problems with repeat administration, Auricchio et al have shown that AAV2/5 can be readministered once to the mouse lung 5 months after the first delivery, ${ }^{61,63}$ and Fischer et al reported successful readministration of AAV2 (three doses) into rhesus macaques. ${ }^{64}$ However, although some low level of GFP reporter gene expression was detected by RT-PCR and via immunohistochemistry, it is unclear how expression levels are compared to one-time administration levels. Importantly, repeated AAV2 administration caused an increase in AAV2-neutralizing antibodies, but did not induce lung inflammation. Most recently, Halbert et al have shown that AAV6-mediated $\alpha 1$-antitrypsin expression in the lungs of mice and dogs persists longer if the animals are immune-suppressed and also demonstrated that cellular immune responses against the viral capsid are mounted even in the immune-suppressed recipients. ${ }^{65}$

On balance, we would argue that AAV vectors may face similar problems with repeat administrations as Ad vectors, but a clinical trial assessing repeat administration of an AAV vector, proven to transduce the human airway epithelium efficiently, is the only way to address this question reliably. Interestingly, Liu et al have recently shown that AAV vectors may be able to transduce progenitor cells in the mouse lung, ${ }^{66}$ which if efficient may help to overcome repeat-administration problems.

Similar to Ad, even in the absence of conclusive proof for efficient repeat administration, AAV vectors have proven useful in preclinical proof-of-principle studies relevant to $\mathrm{CF}$. For example, administration of AAV5-IL10 reduced proinflammatory cytokines and neutrophil infiltration in a mouse model of Pseudomonas aeruginosa infection. ${ }^{67}$

\section{Simian vacuolating virus 40 (SV40)}

Recombinant simian vacuolating virus 40 (rSV40) vectors have been recently used for CFTR gene transfer. SV40 has a circular double-stranded DNA genome and integrates into the genome of transduced cells. The packaging capacity of SV40-based vectors is $\sim 5 \mathrm{~kb}$. To accommodate the large
CFTR cDNA and regulatory elements (two tandem SV40 early promoters), a 'gutless' virus was engineered in which all viral genes were deleted. ${ }^{68}$ Transduction of a CF cell line with rSV40-CFTR led to CFTR protein expression and restored chloride channel function. Administration of rSV40-CFTR to lungs of CF knockout mice infected with Pseudomonas aeruginosa reduced weight loss and inflammation in the treated mice compared to controls. However, $n$ numbers in some of the experiment were fairly small. It has been suggested that recombinant SV40 vectors may not trigger humoral and cellular immune responses and, therefore, may be able to be repeatedly administered. ${ }^{69}$ However, repeat administration to the lungs of animal models has, to the best of our knowledge, not yet been assessed.

\section{RNA viruses Negative-strand cytoplasmic RNA viruses}

In addition to Ad and AAV, various RNA viruses have been validated for airway gene transfer. The murine parainfluenza virus type 1 (or $\mathrm{SeV}$ ), the human respiratory syncytial virus (RSV), and the human parainfluenza virus (PIV) have all been shown efficiently to transfect AECs via the apical membrane ${ }^{15,70}$ using sialic acid and cholesterol, which are abundantly expressed on the apical surface of AECs. These viruses have a negative-strand RNA genome and replicate in the cytoplasm. They neither go through a DNA intermediate, nor enter the nucleus and, therefore, do not carry a risk of insertional mutagenesis. Recently, both PIV and RSV have been used to express CFTR in differentiated CF airway epithelium ex vivo and have been shown partially to correct the CF ion transport defect in this model. However, in vivo studies have not been performed, and the key question about the feasibility of repeat administration remains currently unanswered. ${ }^{71,72}$

Only $\mathrm{SeV}$ has been assessed in animal models in vivo, and is arguably the most efficient vector for transducing AECs. This is due to rapid interaction between the $\mathrm{SeV}$ hemagglutinating/neuraminidase (HN) and the fusion (F) envelope glycoproteins with the cell surface. The HN protein attaches the virus to sialic acid-containing residues on cells and the F protein is responsible for fusing virus and cell membranes with $\mathrm{HN}$ leading to release of the genome into the cytoplasm of the cell. ${ }^{73}$ First-generation recombinant $\mathrm{SeV}$ carrying the CFTR cDNA can produce functional CFTR chloride channels in vitro and after transfection of the nasal epithelium in CF knockout mice in vivo. ${ }^{74}$ In addition, we have used first-generation $\mathrm{SeV}$ vector to produce 
large quantities of the anti-inflammatory cytokine interleukin 10 in mouse airways. ${ }^{75}$ As part of these studies, we demonstrated that the nasal epithelium can be used as an efficient factory for the production of secreted proteins.

Further improvements in the $\mathrm{SeV}$ vectors have been made by deleting the F-protein gene from the viral backbone $(\Delta \mathrm{F})$, which rendered the second-generation viruses transmission incompetent, but did not compromise transduction efficiency. ${ }^{15,76}$ Inoue et al have further improved the $\Delta \mathrm{F} / \mathrm{SeV}$ vector by introducing mutations into the matrix (M) and $\mathrm{HN}$ proteins, which reduce the amount of viruslike particles that are produced after transfection, thereby improving the safety profile. ${ }^{77} \mathrm{SeV}$-mediated gene expression is transient (lasting for about 7 days) and currently, repeated administration to natural hosts (mice) as well as nonnatural hosts (sheep) is not feasible. ${ }^{78}$ Immunomodulatory strategies such as tolerization of mice to $\mathrm{SeV}$ immunodominant epitopes have so far not improved gene expression after repeat administration. ${ }^{79}$

In addition, $\mathrm{SeV}$ lipid envelopes containing the $\mathrm{F}$ and $\mathrm{HN}$ protein, which are crucial for cell uptake, have been used for nonviral gene transfer studies [also known as hemagglutinin virus of Japan (HVJ)-liposomes]. ${ }^{80}$ The $\mathrm{SeV}$ genome is inactivated by, for example, UV irradiation and replaced with nucleic acids such as plasmid DNA. Upon cell contact, the $\mathrm{HN}$ and $\mathrm{F}$ protein in the envelope trigger cell attachment and fusion, respectively, and release the plasmid into the cytoplasm of a target cell. Although proof-of-principle for lung transfection has been demonstrated, efficacy was comparable to other nonviral GTAs ${ }^{81}$ and to the best of our knowledge efficient repeat administration of HVJ-liposomes has not been demonstrated.

Most recently, $\mathrm{SeV}$ has been used to generate induced pluripotent stem cells. The transient and cytoplasmic expression of OCT4, KLF4, SOX2, and c-MYC reduce the risk of vector-induced genome modification and offer a potentially safer alternative to other vectors. ${ }^{82,83}$ Although the usefulness of induced pluripotent stem cells for the treatment of CF is currently unclear, this technology may be useful to generate preclinical models suitable for drug screening and studying basic pathophysiology.

Similar to adenovirus, $\mathrm{SeV}$ has been useful to study the effects of CFTR expression in preclinical models. $\mathrm{SeV}$-mediated CFTR expression in pancreatic duct cells, for example, contributed to an understanding of the link between CFTR expression and bicarbonate transport in this model. ${ }^{84,85}$ However, the use of $\mathrm{SeV}$ will also be restricted to preclinical proof-of-principle studies, until repeat-administration problems can be solved.

\section{Retro- and lentiviruses}

Retroviruses are RNA viruses that are converted to DNA proviruses through reverse transcription before integration into the host genome. Immediately after cloning of the CFTR gene, retroviruses were used for early proof-of-principle studies. One of the first CFTR gene transfer studies performed by Drumm et al used an amphotropic retrovirus carrying CFTR to correct the CF chloride transport defect in vitro. ${ }^{4}$ In vivo studies soon followed and showed that although retroviruses can efficiently transduce undifferentiated regenerating airway epithelium, they failed to transduce nondividing differentiated airway epithelium ${ }^{86}$ and were, therefore, considered to be not particularly useful for $\mathrm{CF}$ gene therapy.

In contrast to oncoretroviral vectors, such as Moloney murine leukemia virus, lentiviral vectors, which also belong to the retroviridae family, are able to transduce nondividing cells and have, therefore, gained a lot of interest from gene therapists. Recombinant human immunodeficiency virus (HIV) is most commonly used, but in the context of lung gene transfer, simian (SIV), ${ }^{87,88}$ feline (FIV), ${ }^{89}$ and equine (EIAV) ${ }^{90}$ immunodeficiency viruses have also been studied. These vectors have a comparatively large packaging capacity of $8-10 \mathrm{~kb},{ }^{91}$ and therefore comfortably fit CFTR and regulatory elements of up to $\sim 5 \mathrm{~kb}$.

Lentiviral vectors are commonly pseudotyped with an envelope glycoprotein from the vesicular stomatitis virus G (VSV-G) allowing for a broad tissue tropism. However, VSVG-pseudotyped vectors are comparatively inefficient at transducing AECs and require the addition of tight-junction openers such as LPC to allow virus entry in airway cells. ${ }^{92,93}$ Several groups, including our own, have attempted to improve further LV uptake into airway epithelium by changing the viral envelope proteins. Glycoproteins from Ebola or Marburg virus that naturally transfect AECs via the apical membrane showed early promise, ${ }^{94}$ but have more recently been superseded by viruses pseudotyped with the influenza M2 envelope glycoprotein, ${ }^{90}$ baculovirus protein GP64 ${ }^{89}$ protein, or the $\mathrm{SeV}$-derived $\mathrm{F}$ and $\mathrm{HN}$ envelope proteins. ${ }^{88}$ Using the F/HN-pseudotyped SIV vector, we achieved $\sim 5 \%$ transduction efficiency of ciliated AECs after administration of $10^{8}$ transduction units per mouse (Figure 1). ${ }^{88}$ This efficiency is in a range that may be considered therapeutically relevant. Importantly, we have also shown that F/HN-SIV transduces fully differentiated human air-liquid interface cultures, which closely resemble human airway epithelium, efficiently ${ }^{88}$ and persistently for at least 18 weeks (unpublished data). 


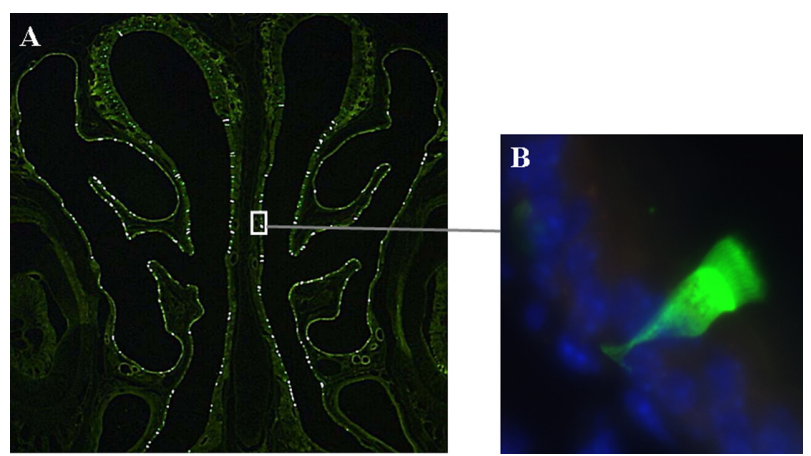

Figure I Transduction of mouse nasal epithelium with F/HN-SIV-GFP. The murine nose was perfused in vivo with F/HN-SIV-GFP $\left(4 \times 10^{8} \mathrm{TU} /\right.$ mouse $)$ vector and gene expression was analyzed 30 days after transduction. A) Microscopic imaging of GFP in histological sections. GFP-positive cells appear as small white punctuate signals. B) Higher magnification of boxed area shows GFP-positive ciliated AEC. Copyright (C) 2010, Elsevier. Reproduced with permission from Mitomo K, Griesenbach U, Inoue $\mathrm{M}$, et al. Toward gene therapy for cystic fibrosis using a lentivirus pseudotyped with Sendai virus envelopes. MolTher. 2010; I8(6): II73-1।82.

Due to LV-mediated integration of the cDNA into the host cell genome, gene expression may theoretically persist for the lifetime of the cell. Importantly, we and others have shown that a single dose of LV to mouse airway epithelium enables reporter gene expression for at least $12-18$ months. ${ }^{88,89} \mathrm{We}$ have recently extended these studies and shown that expression persists for the lifetime of the mice (at least 18-25 months, unpublished data) (Figure 2). Interestingly, Stocker et al have demonstrated that LV-mediated CFTR expression in nasal epithelium of CF knockout mice allows partial correction of the chloride transport to persist for at least 12 months.$^{95}$ It is currently unclear if prolonged expression is due to vector integration into pulmonary stem or progenitor cells or due to the long life expectancy of AECs, which as recently reported, may have a half-life of up to 17 months. ${ }^{96}$

Most importantly, we and others have shown that, in contrast to $\mathrm{Ad}, \mathrm{AAV}$, and $\mathrm{SeV}, \mathrm{LVs}$ can be repeatedly administered to the airways of mice, ${ }^{89,97}$ which is a major requirement for the treatment of chronic diseases such as $\mathrm{CF}$. It is currently unclear how the virus evades the immune system, but this feature as well as the prolonged expression profile make the virus an attractive candidate for $\mathrm{CF}$ gene therapy. Several groups, including the UK CF Gene Therapy Consortium (http://www.cfgenetherapy.org.uk), in collaboration with the CF Trust and DNAVEC Corp. (Japan), are therefore intensively developing this vector for $\mathrm{CF}$. For clinical use, a number of key issues have to be addressed.

1. The field has to confirm that administration of lentiviral vectors to the lungs of $\mathrm{CF}$ patients is safe. The occurrence of leukemia in several severe combined
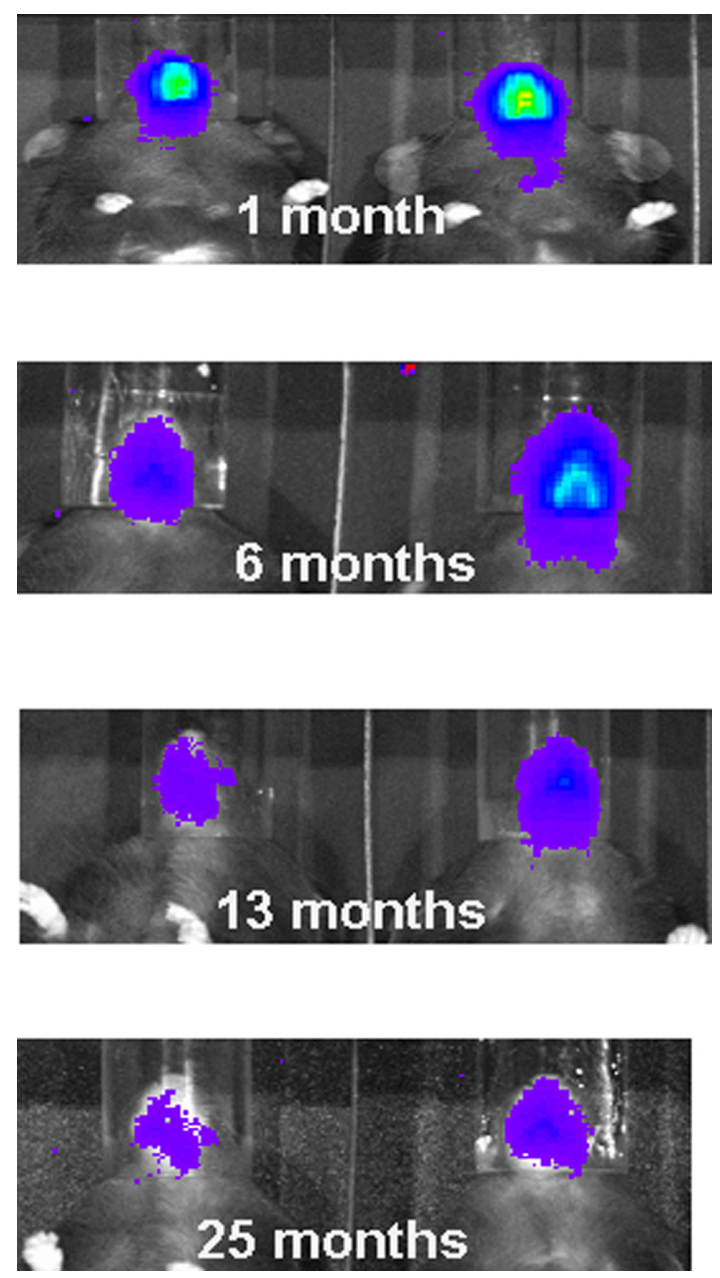

Figure 2 Duration of gene expression after transduction with F/HN-SIV-Luc. Mouse nasal tissue was perfused with F/HN-SIV-Luc $\left(4 \times 10^{8} \mathrm{TU} /\right.$ mouse $)$ and luciferase expression was visualized using bioluminescence in vivo imaging at indicated time points after transduction. Luciferase expression persisted for the lifetime of the mice (at least 18-25 months, unpublished data). Representative images of 2 out of 10 mice are shown.

immunodeficiency subjects after reimplantation of gamma retroviral vector-tranduced bone marrow highlighted that virus-induced insertional mutagenesis is more than a theoretical risk. ${ }^{98}$ When estimating the risk for LV-induced insertional mutagenesis in airways, it is important to consider the following points: i) In contrast to rapidly dividing bone marrow cells, the airway epithelium turns over only slowly and ciliated AECs, which are preferentially transduced with $\mathrm{F} / \mathrm{HN}$-pseudotyped LV are terminally differentiated. ii) In contrast to the gamma retrovirus mentioned above, most lentiviral vectors developed to date are self-inactivating vectors. In these vectors, the $5^{\prime}$ LTR is modified leading to inactivation of the transcription activity of this region and, thereby, reducing the risk of insertional mutagenesis. ${ }^{99}$ iii) In the context of 
bone marrow-based research, it has been demonstrated that eukaryotic promoters such as the elongation factor $1 \alpha$ promoter are safer than strong viral promoters ${ }^{100}$ and we are currently reengineering our F/HN-pseudotyped vector to replace the strong internal cytomegalovirus promoter/enhancer with weaker, but potentially safer, eukaryotic promoter regulatory elements. It is important to note that, to the best of our knowledge, we and others have not observed any evidence of insertional mutagenesis over a 12-month period after LV administration to the lung of mice (unpublished data). However, more detailed studies assessing the integration site profile and biodistribution after LV administration to the airways are urgently required.

Although the risk of insertional mutagenesis with selfinactivating LVs is likely to be low, the development of nonintegrating vectors (NI-LV) may further improve the safety profile of the vector. NI-LV is engineered by introducing mutations into the integrase gene and/or the LTRs and although genome integration may not be completely abolished, most studies have shown that it is significantly reduced. ${ }^{101}$ NI-LVs appear to retain efficient transduction coupled with mostly episome-derived gene expression in slowly turning-over tissues such as muscle and brain, ${ }^{101}$ but have not been assessed in lungs yet. We are currently generating a nonintegrating F/HN-pseudotyped SIV vector to assess the performance of NI-LV in airways. In the longer term, the use of LV that integrates site-specifically into 'safe' locations within the genome may be worth considering. Several groups are currently studying this approach and early proof-of-principle studies based on tethering of virus to specific sites in the genome via sitespecific DNA binding proteins are being employed. ${ }^{102}$

2. In addition to establishing a good safety profile for LV in the lung, the establishment of methods for large-scale virus production is currently a bottleneck that needs to be overcome. Current methods based on either transient transfection ${ }^{103}$ or the use of producer cell lines ${ }^{104}$ followed by purification and concentration of the virus are sufficient to produce high-quality vector for preclinical research in lungs of small animal models. However, improved technology and scale-up will be necessary for progression into larger animal models, toxicology studies, and clinical trials.

3. In parallel to above, methods to ensure efficient delivery to the lungs of CF patients have to be developed. LVs are enveloped viruses and, therefore, comparatively fragile.
We have previously demonstrated that $\mathrm{SeV}$, which have a similar membrane envelope to LV cannot withstand the shear forces in standard jet. ${ }^{78}$ However, single-pass mesh nebulizers such as the eFlow (PARI Pharma, Gräfelfing, Germany) and iNEB technology ${ }^{105}$ may be more appropriate. Encouragingly, preliminary experiments using a single-pass PennCentury syringe spray (PennCentury, Wyndmoor, PA, USA) device ${ }^{106}$ implied that the virus is viable after passing through the device (unpublished data).

A variety of other applications of LV can be envisaged and have in part been assessed.

1. Several groups have shown that in utero gene transfer to airway epithelium is feasible through direct injection of lentiviral vectors into the amniotic fluid. ${ }^{107,108}$ Although this approach may not be directly suitable for clinical application, interesting data have been published. Mishra et al for example, have most recently shown that intraamniotically administered LV may be able to transduce airway stem/progenitor cells capable of contributing to lung injury repair. LV-mediated 'tagging' of these cells may aid the identification and characterization of these difficult-to-study cell populations.

2. Ex vivo transfection of bone marrow-derived stem cells with integrating retro- and lentiviral vectors is a wellestablished, efficient technique. In combination with the concept that bone marrow-derived hematopoietic or mesenchymal stem cells may have the capacity to differentiate into AECs, some groups have speculated that this strategy may have applications for the treatment of CF. However, results are conflicting ${ }^{109}$ and in our view ex vivo transfection and systemic readministration of bone marrow-derived stem cells currently does not hold great promise for $\mathrm{CF}$.

3. In addition to CFTR, expression of other proteins may be of therapeutic benefit in CF. Production of secreted proteins may conceivably be easier in the CF lung than production of the CFTR membrane protein, largely because it may not be critical which and how many cells are transduced. Interestingly, Wilson et al have recently shown that intratracheal administration of a LV-encoding human alpha 1 antitrypsin, a secreted protein, ameliorated the progression of emphysema in a preclinical model. ${ }^{110}$ Importantly, alpha 1 antitrypsin and several other secreted proteases are involved in maintaining an appropriate protease/antiprotease balance in the lung and may be of therapeutic benefit in CF. ${ }^{111}$ 
4. LV vectors have been shown to efficiently express micro RNAs (miRNA) and small hairpin RNAs (shRNA) in various organs in vivo. ${ }^{112,113} \mathrm{LV}$-mediated gene silencing may provide additional opportunities for the treatment of CF. There are several candidate proteins whose inhibition may attenuate CF lung disease. The most obvious is the epithelial sodium channel $(\mathrm{ENaC})$ whose activity is upregulated in $\mathrm{CF}$ and contributes significantly to the imbalanced water movement in the CF lung. The importance of $\mathrm{ENaC}$ as a therapeutic target is also highlighted in studies by Mall et al showing that the ENaC overexpressing transgenic mice develop CF-like lung disease $^{114}$ and by Sheridan et al showing that CF-like lung disease in some subjects is due to ENaC mutations. ${ }^{115} \mathrm{We}$ have shown that, although lipid-complexed antisense and siRNA significantly reduced the mRNA of target proteins in the airway epithelium, they did not translate into a reduction in protein. Inefficient uptake of the silencing oligonucleotides into the airway epithelium was the likely cause. ${ }^{116}$ However, LV-mediated in vivo expression of the silencing molecules may help to overcome this problem.

\section{Conclusion}

Over the last 20 years, the field has spent a significant amount of time evaluating, characterizing, and understanding the strength and weaknesses of various viral GTAs for CF gene therapy. Although studies almost universally show that viral gene transfer to the airways is more efficient than nonviral gene transfer, most viral vectors cause immune responses which interfere with gene expression on redosing and are, therefore, not suitable for $\mathrm{CF}$, a disease which will require life-long expression of the CFTR protein. LVs are currently the only viral vectors that are able to evade the immune system and do not prevent gene expression on redosing. Although the risk/ benefit ratio of $\mathrm{LV}$-mediated gene transfer in $\mathrm{CF}$ has to be carefully studied, this vector currently holds exciting promise for CF gene therapy.

\section{Acknowledgments}

We thank Lucinda Somerton for help with preparation of the manuscript. Our work is funded by the Cystic Fibrosis Trust and the Dr Benjamin Angel Senior Fellowship (UG). The project was supported by the NIHR Respiratory Disease Biomedical Research Unit at the Royal Brompton and Harefield NHS Foundation Trust and Imperial College London.

\section{Disclosure}

The authors report no conflicts of interest in this work.

\section{References}

1. Welsh M, Ramsey BW, Accurso F, Cutting GR. Cystic fibrosis. In: Scriver CR, Beaudet AL, Sly WS, et al, editors. The Metabolic and Molecular Basis of Inherited Disease. New York: McGraw-Hill; 2001: 5121-5188.

2. Riordan JR, Rommens JM, Kerem B, et al. Identification of the cystic fibrosis gene: cloning and characterization of complementary DNA. Science. 1989;245(4922):1066-1073.

3. Alton EW, Middleton PG, Caplen NJ, et al. Non-invasive liposomemediated gene delivery can correct the ion transport defect in cystic fibrosis mutant mice. Nat Genet. 1993;5(2):135-142.

4. Drumm ML, Pope HA, Cliff WH, et al. Correction of the cystic fibrosis defect in vitro by retrovirus-mediated gene transfer. Cell. 1990;62(6): $1227-1233$

5. Griesenbach U, Alton EW. UK Cystic Fibrosis Gene Therapy Consortium. Gene transfer to the lung: lessons learned from more than 2 decades of CF gene therapy. Adv Drug Deliv Rev. 2009; 61(2): 128-139.

6. Sanders N, Rudolph C, Braeckmans K, de Smedt SC, Demeester J. Extracellular barriers in respiratory gene therapy. Adv Drug Deliv Rev. 2009;61(2):115-127.

7. Stern M, Ulrich K, Geddes DM, Alton EW. Poly (D, L-lactideco-glycolide)/DNA microspheres to facilitate prolonged transgene expression in airway epithelium in vitro, ex vivo and in vivo. Gene Ther. 2003;10(16):1282-1288.

8. Yonemitsu Y, Kitson C, Ferrari S, et al. Efficient gene transfer to airway epithelium using recombinant Sendai virus. Nat Biotechnol. 2000;18(9):970-973.

9. Sinn PL, Shah AJ, Donovan MD, McCray PB Jr. Viscoelastic gel formulations enhance airway epithelial gene transfer with viral vectors. Am J Respir Cell Mol Biol. 2005;32(5):404-410.

10. Griesenbach U, Meng C, Farley R, et al. The use of carboxymethylcellulose gel to increase non-viral gene transfer in mouse airways. Biomaterials. 2010;31(9):2665-2672.

11. Chirmule N, Propert K, Magosin S, Qian Y, Qian R, Wilson J. Immune responses to adenovirus and adeno-associated virus in humans. Gene Ther. 1999;6(9):1574-1583.

12. McLachlan G, Davies LA, Gordon C, et al. Repeat aerosol delivery of concentrated PEI/pDNA to the sheep lung [abstract]. Mol Ther. 2010;18(S1):880.

13. Hyde SC, Southern KW, Gileadi U, et al. Repeat administration of DNA/liposomes to the nasal epithelium of patients with cystic fibrosis. Gene Ther. 2000;7(13):1156-1165.

14. Pickles RJ, McCarty D, Matsui H, Hart PJ, Randell SH, Boucher RC. Limited entry of adenovirus vectors into well-differentiated airway epithelium is responsible for inefficient gene transfer. $J$ Virol. 1998; 72(7):6014-6023.

15. Ferrari S, Griesenbach U, Shiraki-Iida T, et al. A defective nontransmissible recombinant Sendai virus mediates efficient gene transfer to airway epithelium in vivo. Gene Ther. 2004;11(22): 1659-1664.

16. Mudhakir $\mathrm{D}$, Harashima $\mathrm{H}$. Learning from the viral journey: how to enter cells and how to overcome intracellular barriers to reach the nucleus. AAPS J. 2009;11(1):65-77.

17. Lam AP, Dean DA. Progress and prospects: nuclear import of nonviral vectors. Gene Ther. 2010;17(4):439-447.

18. Ding W, Zhang L, Yan Z, Engelhardt JF. Intracellular trafficking of adeno-associated viral vectors. Gene Ther. 2005;12(11):873-880.

19. Lee K, Ambrose Z, Martin TD, et al. Flexible use of nuclear import pathways by HIV-1. Cell Host Microbe. 2010;7(3):221-233.

20. Brunetti-Pierri N, Ng P. Progress and prospects: gene therapy for genetic diseases with helper-dependent adenoviral vectors. Gene Ther. 2008; 15(8):553-560. 
21. Zabner J, Couture LA, Gregory RJ, Graham SM, Smith AE, Welsh MJ Adenovirus-mediated gene transfer transiently corrects the chloride transport defect in nasal epithelia of patients with cystic fibrosis. Cell. 1993;75(2):207-216.

22. Walters RW, Grunst T, Bergelson JM, Finberg RW, Welsh MJ, Zabner J. Basolateral localization of fiber receptors limits adenovirus infection from the apical surface of airway epithelia. J Biol Chem. 1999;274(15):10219-10226.

23. Weiss DJ, Beckett T, Bonneau L, Young J, Kolls JK, Wang G. Transient increase in lung epithelial tight junction permeability: an additional mechanism for enhancement of lung transgene expression by perfluorochemical liquids. Mol Ther. 2003;8(6):927-935.

24. Koehler DR, Frndova H, Leung K, et al. Aerosol delivery of an enhanced helper-dependent adenovirus formulation to rabbit lung using an intratracheal catheter. J Gene Med. 2005;7(11):1409-1420.

25. Price AR, Limberis MP, Wilson JM, Diamond SL. Pulmonary delivery of adenovirus vector formulated with dexamethasone-spermine facilitates homologous vector re-administration. Gene Ther. 2007; 14(22):1594-1604.

26. Chirmule N, Raper SE, Burkly L, et al. Readministration of adenovirus vector in nonhuman primate lungs by blockade of CD40-CD40 ligand interactions. J Virol. 2000;74(7):3345-3352.

27. Kolb M, Inman M, Margetts PJ, Galt T, Gauldie J. Budesonide enhances repeated gene transfer and expression in the lung with adenoviral vectors. Am J Respir Crit Care Med. 2001;164(5):866-872.

28. Flotte TR, Ng P, Dylla DE, et al. Viral vector-mediated and cell-based therapies for treatment of cystic fibrosis. Mol Ther. 2007;15(2):229-241.

29. Koehler DR, Sajjan U, Chow YH, et al. Protection of Cftr knockout mice from acute lung infection by a helper-dependent adenoviral vector expressing Cftr in airway epithelia. Proc Natl Acad Sci U S A. 2003; 100(26): 15364-15369.

30. van Heeckeren AM, Scaria A, Schluchter MD, Ferkol TW, Wadsworth S, Davis PB. Delivery of CFTR by adenoviral vector to cystic fibrosis mouse lung in a model of chronic Pseudomonas aeruginosa lung infection. Am J Physiol Lung Cell Mol Physiol. 2004;286(4):L717-L726.

31. Larson JE, Morrow SL, Happel L, Sharp JF, Cohen JC. Reversal of cystic fibrosis phenotype in mice by gene therapy in utero. Lancet. 1997;349(9052):619-620.

32. Buckley SM, Waddington SN, Jezzard S, et al. Intra-amniotic delivery of CFTR-expressing adenovirus does not reverse cystic fibrosis phenotype in inbred CFTR-knockout mice. Mol Ther. 2008;16(5): 819-824

33. Davies LA, Varathalingam A, Painter H, et al. Adenovirus-mediated in utero expression of CFTR does not improve survival of CFTR knockout mice. Mol Ther. 2008;16(5):812-818.

34. Meyerholz DK, Stoltz DA, Pezzulo AA, Welsh MJ. Pathology of gastrointestinal organs in a porcine model of cystic fibrosis. Am J Pathol. 2010;176(3):1377-1389.

35. Duan D, Sharma P, Yang J, et al. Circular intermediates of recombinant adeno-associated virus have defined structural characteristics responsible for long-term episomal persistence in muscle tissue. J Virol. 1998;72(11):8568-8577.

36. Flotte TR. Recent developments in recombinant AAV-mediated gene therapy for lung diseases. Curr Gene Ther. 2005;5(3):361-366.

37. McCarty DM, Young SM Jr, Samulski RJ. Integration of adenoassociated virus (AAV) and recombinant AAV vectors. Annu Rev Genet. 2004;38:819-845.

38. Moss RB, Rodman D, Spencer LT, et al. Repeated adeno-associated virus serotype 2 aerosol-mediated cystic fibrosis transmembrane regulator gene transfer to the lungs of patients with cystic fibrosis: a multicenter, double-blind, placebo-controlled trial. Chest. 2004; 125(2):509-521.

39. Moss RB, Milla C, Colombo J, et al. Repeated aerosolized AAV-CFTR for treatment of cystic fibrosis: a randomized placebo-controlled phase 2B trial. Hum Gene Ther. 2007;18(8):726-732.

40. Gao G, Vandenberghe LH, Wilson JM. New recombinant serotypes of AAV vectors. Curr Gene Ther. 2005;5(3):285-297.
41. Limberis MP, Vandenberghe LH, Zhang L, Pickles RJ, Wilson JM. Transduction efficiencies of novel AAV vectors in mouse airway epithelium in vivo and human ciliated airway epithelium in vitro. Mol Ther. 2009;17(2):294-301.

42. Xie Q, Bu W, Bhatia S, et al. The atomic structure of adeno-associated virus (AAV-2), a vector for human gene therapy. Proc Natl Acad Sci US A. 2002;99(16):10405-10410.

43. Shi W, Bartlett JS. RGD inclusion in VP3 provides adeno-associated virus type 2 (AAV2)-based vectors with a heparan sulfate-independent cell entry mechanism. Mol Ther. 2003;7(4):515-525

44. White AF, Mazur M, Sorscher EJ, Zinn KR, Ponnazhagan S. Genetic modification of adeno-associated viral vector type 2 capsid enhances gene transfer efficiency in polarized human airway epithelial cells. Hum Gene Ther. 2008;19(12):1407-1414.

45. Maheshri N, Koerber JT, Kaspar BK, Schaffer DV. Directed evolution of adeno-associated virus yields enhanced gene delivery vectors. Nat Biotechnol. 2006;24(2):198-204.

46. Excoffon KJ, Koerber JT, Dickey DD, et al. Directed evolution of adeno-associated virus to an infectious respiratory virus. Proc Natl Acad Sci U S A. 2009;106(10):3865-3870.

47. Li W, Zhang L, Johnson JS, et al. Generation of novel AAV variants by directed evolution for improved CFTR delivery to human ciliated airway epithelium. Mol Ther. 2009;17(12):2067-2077.

48. Liu X, Luo M, Guo C, Yan Z, Wang Y, Engelhardt JF. Comparative biology of rAAV transduction in ferret, pig and human airway epithelia. Gene Ther. 2007;14(21):1543-1548.

49. Ding W, Yan Z, Zak R, Saavedra M, Rodman DM, Engelhardt JF. Second-strand genome conversion of adeno-associated virus type 2 (AAV-2) and AAV-5 is not rate limiting following apical infection of polarized human airway epithelia. J Virol. 2003;77(13):7361-7366.

50. Yan Z, Lei-Butters DC, Zhang Y, Zak R, Engelhardt JF. Hybrid adenoassociated virus bearing nonhomologous inverted terminal repeats enhances dual-vector reconstruction of minigenes in vivo. Hum Gene Ther. 2007;18(1):81-87.

51. Zhang LN, Karp P, Gerard CJ, et al. Dual therapeutic utility of proteasome modulating agents for pharmaco-gene therapy of the cystic fibrosis airway. Mol Ther. 2004;10(6):990-1002.

52. Duan D, Yue Y, Engelhardt JF. Expanding AAV packaging capacity with trans-splicing or overlapping vectors: a quantitative comparison. Mol Ther. 2001;4(4):383-391.

53. Halbert CL, Allen JM, Miller AD. Efficient mouse airway transduction following recombination between AAV vectors carrying parts of a larger gene. Nat Biotechnol. 2002;20(7):697-701.

54. Song Y, Lou HH, Boyer JL, et al. Functional cystic fibrosis transmembrane conductance regulator expression in cystic fibrosis airway epithelial cells by AAV6.2-mediated segmental trans-splicing. Hum Gene Ther. 2009;20(3):267-281.

55. Ostedgaard LS, Rokhlina T, Karp PH, et al. A shortened adeno-associated virus expression cassette for CFTR gene transfer to cystic fibrosis airway epithelia. Proc Natl Acad Sci U S A. 2005; 102(8):2952-2957.

56. Fischer AC, Smith CI, Cebotaru L, et al. Expression of a truncated cystic fibrosis transmembrane conductance regulator with an AAV5-pseudotyped vector in primates. Mol Ther. 2007;15(4): 756-763.

57. Mueller C, Torrez D, Braag S, et al. Partial correction of the CFTRdependent ABPA mouse model with recombinant adeno-associated virus gene transfer of truncated CFTR gene. J Gene Med. 2008; 10(1):51-60.

58. Allocca M, Doria M, Petrillo M, et al. Serotype-dependent packaging of large genes in adeno-associated viral vectors results in effective gene delivery in mice. J Clin Invest. 2008;118(5):1955-1964.

59. Halbert CL, Lam SL, Miller AD. High-efficiency promoter-dependent transduction by adeno-associated virus type 6 vectors in mouse lung. Hum Gene Ther. 2007;18(4):344-354.

60. Beck SE, Jones LA, Chesnut K, et al. Repeated delivery of adenoassociated virus vectors to the rabbit airway. J Virol. 1999;73(11): 9446-9455. 
61. Halbert CL, Standaert TA, Aitken ML, Alexander IE, Russell DW, Miller AD. Transduction by adeno-associated virus vectors in the rabbit airway: efficiency, persistence, and readministration. $J$ Virol. 1997;71(8):5932-5941.

62. Halbert CL, Rutledge EA, Allen JM, Russell DW, Miller AD. Repeat transduction in the mouse lung by using adeno-associated virus vectors with different serotypes. J Virol. 2000;74(3):1524-1532.

63. Auricchio A, O'Connor E, Weiner D, et al. Noninvasive gene transfer to the lung for systemic delivery of therapeutic proteins. J Clin Invest. 2002;110(4):499-504.

64. Fischer AC, Beck SE, Smith CI, et al. Successful transgene expression with serial doses of aerosolized rAAV2 vectors in rhesus macaques. Mol Ther. 2003;8(6):918-926.

65. Halbert CL, Madtes DK, Vaughan AE, et al. Expression of human alpha1-antitrypsin in mice and dogs following AAV6 vector-mediated gene transfer to the lungs. Mol Ther. 2010;18(6): 1165-1172.

66. Liu X, Luo M, Guo C, et al. Analysis of adeno-associated virus progenitor cell transduction in mouse lung. Mol Ther. 2009;17(2): 285-293.

67. Buff SM, Yu H, McCall JN, et al. IL-10 delivery by AAV5 vector attenuates inflammation in mice with pseudomonas pneumonia. Gene Ther. 2010;17(5):567-576.

68. Mueller C, Strayer MS, Sirninger J, et al. In vitro and in vivo functional characterization of gutless recombinant SV40-derived CFTR vectors. Gene Ther. 2010;17(2):227-237.

69. Kondo R, Feitelson MA, Strayer DS. Use of SV40 to immunize against hepatitis B surface antigen: implications for the use of SV40 for gene transduction and its use as an immunizing agent. Gene Ther. 1998;5(5):575-582.

70. Zhang L, Bukreyev A, Thompson CI, et al. Infection of ciliated cells by human parainfluenza virus type 3 in an in vitro model of human airway epithelium. J Virol. 2005;79(2):1113-1124.

71. Zhang L, Button B, Gabriel SE, et al. CFTR delivery to $25 \%$ of surface epithelial cells restores normal rates of mucus transport to human cystic fibrosis airway epithelium. PLoS Biol. 2009;7(7):e1000155.

72. Kwilas AR, Yednak MA, Zhang L, et al. Respiratory syncytial virus engineered to express the cystic fibrosis transmembrane conductance regulator corrects the bioelectric phenotype of human cystic fibrosis airway epithelium in vitro. J Virol. 2010;84(15):7770-7781.

73. Okada Y. Sendai virus-induced cell fusion. Methods Enzymol. 1993; 221:18-41.

74. Ferrari S, Griesenbach U, Iida A, et al. Sendai virus-mediated CFTR gene transfer to the airway epithelium. Gene Ther. 2007; 14(19):1371-1379.

75. Griesenbach U, Cassady RL, Ferrari S, et al. The nasal epithelium as a factory for systemic protein delivery. Mol Ther. 2002;5(2):98-103.

76. Li HO, Zhu YF, Asakawa M, et al. A cytoplasmic RNA vector derived from nontransmissible Sendai virus with efficient gene transfer and expression. J Virol. 2000;74(14):6564-6569.

77. Inoue $\mathrm{M}$, Tokusumi $\mathrm{Y}$, Ban $\mathrm{H}$, et al. Nontransmissible virus-like particle formation by F-deficient Sendai virus is temperature sensitive and reduced by mutations in $\mathrm{M}$ and $\mathrm{HN}$ proteins. $J$ Virol. 2003;77(5):3238-3246.

78. Griesenbach U, McLachlan G, Owaki T, et al. Validation of recombinant Sendai virus in a non-natural host model. Gene Ther. 2010; In press.

79. Griesenbach U, Geddes DM, Alton EW. Gene therapy progress and prospects: cystic fibrosis. Gene Ther. 2006;13(14):1061-1067.

80. Zhang Q, Li Y, Shi Y, Zhang Y. HVJ envelope vector, a versatile delivery system: its development, application, and perspectives. Biochem Biophys Res Commun. 2008;373(3):345-349.

81. Kaneda Y, Nakajima T, Nishikawa T, et al. Hemagglutinating virus of Japan (HVJ) envelope vector as a versatile gene delivery system. Mol Ther. 2002;6(2):219-226.

82. Fusaki N, Ban H, Nishiyama A, Saeki K, Hasegawa M. Efficient induction of transgene-free human pluripotent stem cells using a vector based on Sendai virus, an RNA virus that does not integrate into the host genome. Proc Jpn Acad Ser B Phys Biol Sci. 2009;85(8): 348-362.
83. Seki T, Yuasa S, Oda M, et al. Generation of induced pluripotent stem cells from human terminally differentiated circulating T cells. Cell Stem Cell. 2010;7(1):11-14.

84. Rakonczay Z Jr, Hegyi P, Hasegawa M, et al. CFTR gene transfer to human cystic fibrosis pancreatic duct cells using a Sendai virus vector. J Cell Physiol. 2008;214(2):442-455.

85. Ignath I, Hegyi P, Venglovecz V, et al. CFTR expression but not $\mathrm{Cl}$ - transport is involved in the stimulatory effect of bile acids on apical Cl-/HCO3- exchange activity in human pancreatic duct cells. Pancreas. 2009;38(8):921-929.

86. Engelhardt JF, Yankaskas JR, Wilson JM. In vivo retroviral gene transfer into human bronchial epithelia of xenografts. J Clin Invest. 1992;90(6):2598-2607.

87. Kobayashi M, Iida A, Ueda Y, Hasegawa M. Pseudotyped lentivirus vectors derived from simian immunodeficiency virus SIVagm with envelope glycoproteins from paramyxovirus. $J$ Virol. 2003;77(4):2607-2614.

88. Mitomo K, Griesenbach U, Inoue M, et al. Toward gene therapy for cystic fibrosis using a lentivirus pseudotyped with Sendai virus envelopes. Mol Ther. 2010;18(6):1173-1182.

89. Sinn PL, Arias AC, Brogden KA, McCray PB Jr. Lentivirus vector can be readministered to nasal epithelia without blocking immune responses. J Virol. 2008;82(21):10684-10692.

90. McKay T, Patel M, Pickles RJ, Johnson LG, Olsen JC. Influenza M2 envelope protein augments avian influenza hemagglutinin pseudotyping of lentiviral vectors. Gene Ther. 2006;13(8):715-724.

91. Sinn PL, Sauter SL, McCray PB Jr. Gene therapy progress and prospects: development of improved lentiviral and retroviral vectors-design, biosafety, and production. Gene Ther. 2005;12(14):1089-1098.

92. Limberis M, Anson DS, Fuller M, Parsons DW. Recovery of airway cystic fibrosis transmembrane conductance regulator function in mice with cystic fibrosis after single-dose lentivirus-mediated gene transfer. Hum Gene Ther. 2002;13(16):1961-1970.

93. Cmielewski P, Anson DS, Parsons DW. Lysophosphatidylcholine as an adjuvant for lentiviral vector mediated gene transfer to airway epithelium: effect of acyl chain length. Respir Res. 2010; 11(1):84.

94. Medina MF, Kobinger GP, Rux J, et al. Lentiviral vectors pseudotyped with minimal filovirus envelopes increased gene transfer in murine lung. Mol Ther. 2003;8(5):777-789.

95. Stocker AG, Kremer KL, Koldej R, Miller DS, Anson DS, Parsons DW. Single-dose lentiviral gene transfer for lifetime airway gene expression. J Gene Med. 2009;11(10):861-867.

96. Rawlins EL, Hogan BL. Ciliated epithelial cell lifespan in the mouse trachea and lung. Am J Physiol Lung Cell Mol Physiol. 2008; 295(1):L231-L234.

97. Griesenbach U, Mitomo K, Inoue M, et al. Repeat administration of Sendai virus-F/HN pseudotyped lentivirus vector to the respiratory epithelium is feasible [abstract]. Mol Ther. 2008;1(16):A754.

98. Howe SJ, Mansour MR, Schwarzwaelder K, et al. Insertional mutagenesis combined with acquired somatic mutations causes leukemogenesis following gene therapy of SCID-X1 patients. J Clin Invest. 2008;118(9):3143-3150.

99. Zufferey R, Dull T, Mandel RJ, et al. Self-inactivating lentivirus vector for safe and efficient in vivo gene delivery. J Virol. 1998; 72(12):9873-9880.

100. Montini E, Cesana D, Schmidt M, et al. The genotoxic potential of retroviral vectors is strongly modulated by vector design and integration site selection in a mouse model of HSC gene therapy. JClin Invest. 2009;119(4):964-975.

101. Wanisch K, Yanez-Munoz RJ. Integration-deficient lentiviral vectors: a slow coming of age. Mol Ther. 2009;17(8):1316-1332.

102. Su K, Wang D, Ye J, Kim YC, Chow SA. Site-specific integration of retroviral DNA in human cells using fusion proteins consisting of human immunodeficiency virus type 1 integrase and the designed polydactyl zinc-finger protein E2C. Methods. 2009;47(4): 269-276. 
103. Kutner RH, Zhang XY, Reiser J. Production, concentration and titration of pseudotyped HIV-1-based lentiviral vectors. Nat Protoc. 2009;4(4):495-505.

104. Ikeda Y, Takeuchi Y, Martin F, Cosset FL, Mitrophanous K, Collins M. Continuous high-titer HIV-1 vector production. Nat Biotechnol. 2003;21(5):569-572.

105. Denyer J, Dyche T. The Adaptive Aerosol Delivery (AAD) technology: past, present, and future. J Aerosol Med Pulm Drug Deliv. 2010;23 Suppl 1:S1-S10.

106. Beck SE, Laube BL, Barberena CI, et al. Deposition and expression of aerosolized rAAV vectors in the lungs of Rhesus macaques. Mol Ther. 2002;6(4):546-554.

107. Buckley SM, Howe SJ, Sheard V, et al. Lentiviral transduction of the murine lung provides efficient pseudotype and developmental stage-dependent cell-specific transgene expression. Gene Ther. 2008; 15(16):1167-1175.

108. Mishra S, Wang X, Smiley N, et al. Genetic modification of airway progenitors following lentiviral gene delivery to the amniotic fluid of murine fetuses. Am J Respir Cell Mol Biol. 2010: Jun 25 [Epub ahead of print].

109. Sage EK, Leobinger MR, Polak J, Janes SM. The role of bone marrowderived stem cells in lung regeneration and repair. In: Melton D, Girad L, editors. StemBook. Cambridge (MA): Harvard Stem Cell Institute; 2008.
110. Wilson AA, Murphy GJ, Hamakawa H, et al. Amelioration of emphysema in mice through lentiviral transduction of long-lived pulmonary alveolar macrophages. J Clin Invest. 2010;120(1): 379-389.

111. Griese M, Latzin P, Kappler M, et al. alpha1-Antitrypsin inhalation reduces airway inflammation in cystic fibrosis patients. Eur Respir J. 2007;29(2):240-250.

112. Huang HY, Lee CC, Chiang BL. Short hairpin RNAs against eotaxin or interleukin-5 decrease airway eosinophilia and hyper-responsiveness in a murine model of asthma. J Gene Med. 2009;11(2): 112-118.

113. Scherr M, Venturini L, Eder M. Lentiviral vector-mediated expression of pre-miRNAs and antagomiRs. Methods Mol Biol. 2010;614: 175-185.

114. Mall M, Grubb BR, Harkema JR, O’Neal WK, Boucher RC. Increased airway epithelial $\mathrm{Na}+$ absorption produces cystic fibrosis-like lung disease in mice. Nat Med. 2004;10(5):487-493.

115. Sheridan MB, Fong P, Groman JD, et al. Mutations in the beta-subunit of the epithelial $\mathrm{Na}+$ channel in patients with a cystic fibrosis-like syndrome. Hum Mol Genet. 2005;14(22):3493-3498.

116. Griesenbach U, Wasowicz MY, Smith SN, et al. Endpoint assay development and validation of non-viral gene transfer agents in CF mice [abstract]. Pediatr Pulmol. 2005;S28:270.
Virus Adaptation and Treatment

\section{Publish your work in this journal}

Virus Adaptation and Treatment is an international, peer-reviewed open access journal focusing on the study of virology, viral adaptation and the development and use of antiviral drugs and vaccines to achieve improved outcomes in infection control and treatment. The journa welcomes original research, basic science, clinical \& epidemiological

\section{Dovepress}

studies, reviews \& evaluations, expert opinion and commentary, case reports and extended reports. The manuscript management system is completely online and includes a very quick and fair peer-review system, which is all easy to use. Visit http://www.dovepress.com/ testimonials.php to read real quotes from published authors. 